\title{
VIII International Conference Mechanisms of Catalytic Reactions (MCR-2009) Dedicated to the 70th Anniversary of Professor K.I. Zamaraev ${ }^{1}$
}

\author{
Novosibirsk Scientific Center, Russia \\ http://www-sbras.nsc.ru/ws/MCR-ZAM/index.en.html
}

DOI: $10.1134 / \mathrm{S} 0023158409010200$

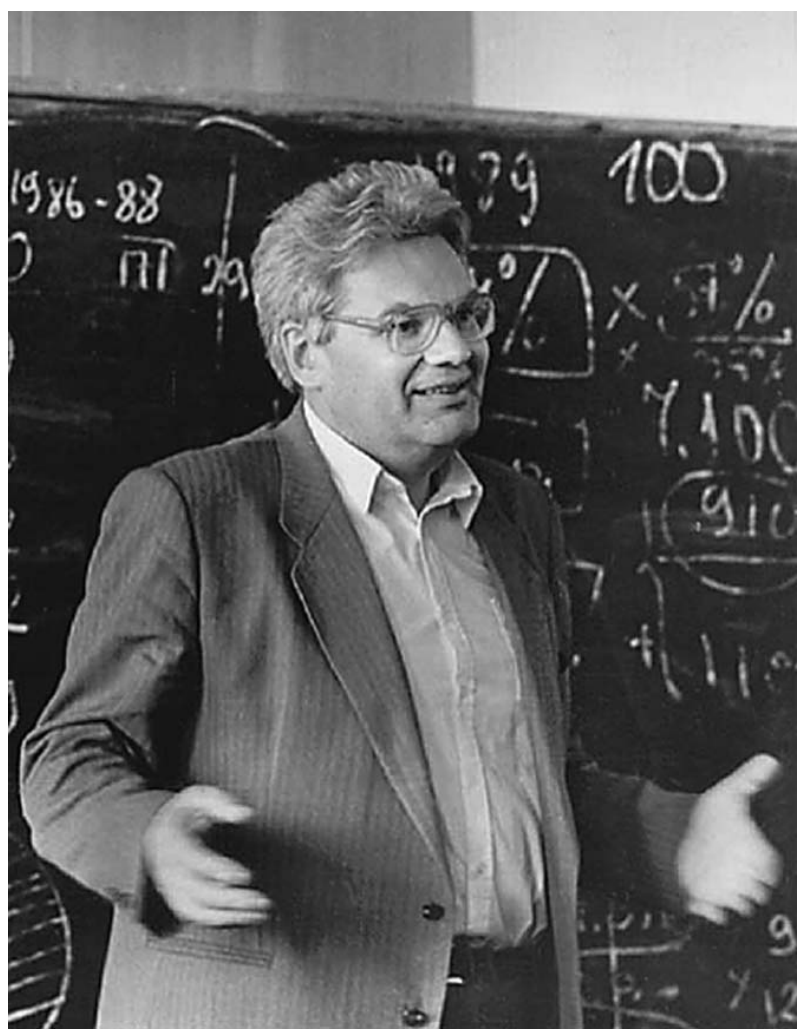

Dear Colleagues,

We are pleased to invite you to participate in the VIII International Conference "Mechanisms of Catalytic Reactions" to commemorate the 70th anniversary of the birth of Professor Kirill I. Zamaraev. The Conference will be held in Novosibirsk (Russia) on June 28-July 2, 2009.

\section{Organizing Committee}

Professor Kirill Il'ich Zamaraev (1939-1996) was one of the pre-eminent physical chemists. His main field of interest was the application of new physicochemical techniques to the investigation of mechanisms of homogeneous and heterogeneous catalytic reactions.

\footnotetext{
${ }^{1}$ The article is published in the original.
}

An extraordinary scientist, talented teacher, and statesman, Professor Zamaraev was Director of the Boreskov Institute of Catalysis (1984-1995) and President of the International Union of Pure and Applied Chemistry (1994-1995).

\section{Conference Organizers}

- Siberian Branch of the Russian Academy of Sciences (SB RAS);

-Ministry of Education and Science of the Russian Federation, Moscow;

- Scientific Council on Catalysis, RAS;

-Boreskov Institute of Catalysis, SB RAS, Novosibirsk, Russia;

-Moscow State University, Moscow, Russia;

-Russian Mendeleev Chemical Society, Novosibirsk Department, Russia.

\section{Scientific Program}

International Conferences "Mechanisms of Catalytic Reactions" have a status of a regular international conference devoted to the most complicated problems of modern physical chemistry and catalysis:

(1) Mechanisms of homogeneous and heterogeneous catalysis at the atomic and molecular scales;

(2) Physical methods for the study of mechanisms of heterogeneous and homogeneous catalytic reactions, including in situ techniques;

(3) Theory and quantum-mechanical approaches in catalysis;

(4) Catalysis in nature, biomimetic catalysis, and photocatalysis.

Persons who plan to attend the Conference are kindly requested to register at the Conference website http://www-sbras.nsc.ru/ws/MCR-ZAM/index.en.html and submit their abstracts as email attachments to star@catalysis.ru before January 25, 2009. 